\title{
Efectos de la afluencia humana durante la etapa de auge algodonero en el Chaco (1920-1944). Un abordaje a partir de información oficial, y testimonios de época*
}

\author{
Effects of human influx during the cotton boom phase in the Chaco \\ (1920-1944). An approach based on official information, and \\ testimonials of time.
}

\section{Oscar Ernesto Mari**}

\section{RESUMO}

Durante las décadas del veinte y treinta del siglo XX, el Chaco, que era uno de los Territorios Nacionales argentinos, tuvo uno de los procesos socioeconómicos más notables del país a raíz del éxito obtenido con el cultivo e industrialización primaria del algodón. Ello motivó la atracción de fuertes contingentes inmigratorios internos y externos que arribaron a esta jurisdicción para beneficiarse del demandante mercado de trabajo. Incluidos en estos contingentes estuvieron los miles de trabajadores temporarios que periódicamente ingresaron al Territorio para participar de la cosecha manual del textil. Estos masivos ingresos provocaron el desborde de la administración local, que no pudo satisfacer con eficacia los requerimientos de una población en constante aumento. Algunas consecuencias de este fenómeno, particularmente las vinculadas al control social, habrán de ser analizadas en este artículo utilizando las referencias de gobernadores, y protagonistas calificados de la época.

Palabras clave: Chaco. Territorio. Algodón. Cuestión social.

\section{ABSTRACT}

During the twenties and thirties of the twentieth century, the Chaco, which was one of the Argentine National Territories, was one of the most remarkable socio-economic processes in the country following

* Este trabajo ha sido financiado por el CONICET, Argentina.

** Doctor en Historia por la Universidad del Salvador, Argentina. Investigador Independiente del CONICET, con sede de trabajo en el IIGHI-CONICET-UNNE. Profesor regular de la Facultad de Humanidades de la Universidad Nacional del Nordeste, Resistencia, Chaco, Argentina. E Mail: oscar.mari@yahoo.com.ar 
the success of the primary culture and industrialization of cotton. This motivated the attraction of strong internal and external immigration quotas that arrived in this jurisdiction for plaintiff's benefit labor market. Included in these quotas were the thousands of temporary workers who regularly entered the Territory to participate in manual harvesting textiles. These massive revenues caused the overflow of local government, which could not effectively meet the needs of a growing population. Some consequences of this phenomenon, particularly those related to social control, must be analyzed in this article using the references of the governors, and skilled players of the era.

Keywords: Chaco. Territory. Cotton. Social issue.

\section{Introducción}

En 1935 el destacado escritor y político socialista chaqueño Juan Ramón Lestani publicó un fascículo en donde expresó su opinión sobre algunas cuestiones que lo inquietaban respecto a su tierra natal. El folleto, titulado "El Territorio Nacional del Chaco. Geográfico, Político y Social", llevó también el sugestivo subtítulo "Oro y Miseria", y con estas dos palabras el autor preanunció en cierta forma el contenido de su escrito, y también la dicotomía que observaba en el Chaco de aquella época en su condición de dirigente comprometido.

Entre otros conceptos, Lestani expresaba en su prólogo:

[...]Oro y Miseria; así es el Chaco... Presento al Chaco económico, industrial y comercial, cuyo portentoso desarrollo llama la atención de los financistas que agitan a todos los vientos sus posibilidades, pero que ocultan en su entusiasmo la miseria que se esconde bajo ese brillo enceguecedor (LESTANI, 1935, p. 3).

Se refería de esta manera a la vulnerabilidad de una parte de la población de este Territorio, que pese a encontrar aquí promisorias posibilidades de progreso, por distintos motivos se hallaba expuesta a cierta marginación por parte de los poderes públicos, o a los abusos provenientes de los privados.

Dedicó diversos pasajes de su escrito a lo que ya entonces era una realidad conocida pero convenientemente soslayada: las precarias y en algunos casos, lamentables condiciones de vida y trabajo de algunos grupos humanos vinculados a las tareas manuales de las entonces preeminentes actividades del mundo rural: las forestales, y las algodoneras. “...La inhumanidad del trato es indescriptible, y la explotación del trabajador no tiene límites...", decía al graficar las labores en los obrajes forestales; y como "parias" y "esclavos" catalogó a cosecheros, puesteros, obreros de fábricas y comercios, e inclusive a colonos, justificando en 
todos los casos los argumentos que utilizó para sostener lo que definió como un "hiriente alegato" para llamar la atención de la sociedad local y nacional.

Por la misma época, otros dirigentes locales de distinta ideología, y naturalmente de posiciones opuestas, se ocuparon también de monitorear, y en algunos casos, de proponer soluciones a la problemática social surgida en el Chaco -especialmente- como consecuencia de la extraordinaria afluencia humana atraída por el auge algodonero.

Uno de estos referentes fue José Conrado Castells, gobernador del Territorio durante dos períodos consecutivos (1933-38), quien amerita ser considerado en este análisis no sólo por haber contado con excepcionales cualidades para un funcionario de esta categoría en esa época, sino también por haber tenido un activo papel en la evaluación e intentos de solución a la temática socioeconómica del Chaco, precisamente en el momento de mayor efervescencia del proceso vinculado al cultivo del textil.

Parte de lo que aquí se expone proviene de las referencias o informes elaborados por éstos y otros destacados hombres públicos locales o extra-regionales que supieron sacar a la luz cuestiones que hasta entonces no habían merecido atención suficiente, instalando de esta forma un incipiente debate público sobre algunos puntos de la problemática social en el Chaco.

Nuestro interés es comentar, con la perspectiva que permite el paso del tiempo, algunos aspectos de esa cuestión social, tomando como base las consideraciones de esos observadores contemporáneos, pero ofreciendo en este caso, una mirada enfocada específicamente en las condiciones y formas de vida de los grupos que tuvieron mayor presencia demográfica en el ámbito rural del Territorio.

Entendemos, por ejemplo, que los estudios sobre los hábitos, costumbres, y respectivas problemáticas de los sectores más numerosos que habitaron el ámbito rural del Chaco en esta época, brindan elementos muy interesantes para conocer parte de la vida cotidiana en ese entorno, y permiten lograr una mejor aproximación a una realidad en permanente cambio, dada la vertiginosidad de los procesos socio-económicos por entonces en curso.

En las páginas siguientes buscaremos, en principio, dar una visión muy sintética del proceso de poblamiento ocurrido en el Chaco durante el período de transición entre el ciclo económico llamado forestal, y el subsiguiente, vinculado al cultivo algodonero, los cuales coexistieron durante el período que tratamos.

Procuraremos en este apartado brindar un panorama de lo que significó para el Chaco, sobre todo en términos demográficos, el éxito del cultivo algodonero en su condición de imán demandante de mano de obra temporaria, especialmente entre las décadas del veinte y cuarenta. 
Seguidamente nos detendremos un poco más en analizar la composición de los grupos humanos que llegaron atraídos por esa demanda; en qué condiciones residieron en el Territorio; qué fenómenos o problemas surgieron a raíz de estos periódicos y multitudinarios ingresos, y de qué manera fueron interpretados por los observadores contemporáneos o las autoridades de turno.

\section{Los grupos sociales del ámbito rural del Chaco durante la transición del ciclo forestal al algodonero}

Al igual que los demás Territorios Nacionales organizados en la Argentina en 1884, el Chaco recibió un régimen político-institucional uniforme y un proyecto de poblamiento basado en la incorporación de inmigración interna y externa.

En el caso de este Territorio, dicha incorporación se dio fundamentalmente en tres momentos más o menos definidos, que coincidieron a su vez con los tres ciclos socioeconómicos oportunamente diferenciados por el historiador chaqueño Guido Miranda, y sobre los cuales, existe un amplio consenso en lo referido a su pertinencia.

En el primero de ellos, denominado Fundación, el poblamiento "blanco" se realizó con los primeros inmigrantes europeos que se establecieron en el Este del Territorio, próximos a la confluencia de los grandes ríos Paraná, Paraguay, y Bermejo. Este proceso se produjo durante las dos últimas décadas del siglo XIX, cuando la mayor parte del Chaco estaba aún bajo dominio indígena.

El segundo momento de ocupación del espacio estuvo asociado al llamado ciclo forestal o del Tanino, y como consecuencia de las actividades vinculadas, el poblamiento se fue expandiendo hacia los márgenes del área inicialmente colonizada. Esta etapa perduró en todo su esplendor hasta la culminación de la primera guerra mundial, luego de lo cual comienza a decaer (pero no desaparecer) debido a la retracción de la demanda internacional de los productos forestales del Chaco. Esta actividad motivó un importante ingreso de trabajadores manuales provenientes de las provincias vecinas y del Paraguay, que se dedicaron a las labores en los obrajes (hacheros), y en las fábricas de tanino.

Casi simultáneamente a la declinación del ciclo forestal se abrirá una nueva etapa en el poblamiento del Chaco debido a factores concurrentes. Con la finalización de los ramales ferroviarios troncales que atravesaron el Territorio vinculándolo con las provincias circundantes, juntamente con la incorporación de las tierras del centro, norte y oeste que se destinarán a la explotación agrícola, dará comienzo el llamado ciclo algodonero, puesto que la mayor parte de estas extensiones ganadas se destinarán al cultivo del textil, que halló en 
estas latitudes, condiciones inmejorables para su desarrollo, en sintonía con la creciente demanda mundial del producto.

El éxito del cultivo, los altos precios internacionales, y la posibilidad de acceder a la tierra fiscal atrajeron una fuerte oleada inmigratoria que hará multiplicar repetidamente la población del Territorio durante las décadas del veinte y treinta. Los inmigrantes provinieron esta vez fundamentalmente de la Europa del Este, y se instalaron en las colonias creadas en el centro y sud-oeste del Chaco, dedicándose mayoritariamente a la explotación más redituable: el cultivo algodonero.

Ello a su vez generó una sinergia adicional; el cultivo (carpida) y la cosecha del textil demandaron gran cantidad de mano de obra, y esto es precisamente lo que atrajo a nutridos contingentes de trabajadores temporarios (braceros), que en periódica y aluvial afluencia, participaron anualmente de cada campaña.

Estos miles de trabajadores manuales provinieron, al igual que en el ciclo forestal, de las provincias vecinas, trayendo consigo en cada temporada, todo el acervo cultural característico de sus lugares de origen.

De esta forma, el ciclo algodonero significó para el Chaco una etapa de grandes transformaciones. Hacia fines de la década del veinte podía advertirse con claridad que la fisonomía del Chaco cambiaba aceleradamente. Demográficamente su crecimiento avanzó con un ritmo formidable: en 1920 había 60.000 habitantes; en 1925 los cálculos hablan ya de 110.000; el censo Territorial realizado por el gobernador Castells en 1934 establece la población en 214.160 habitantes; para 1936 se calculan ya en 276.000; y para 1940, el estimado era de 360.000 habitantes.

Este fue, sin duda, uno de los procesos socioeconómicos más notables de la Argentina en el período, y el Chaco sobrepasó así a varias antiguas provincias, tanto en crecimiento económico como poblacional.

Debido a las características descriptas, aún suele considerarse al Chaco como espacio receptor de un "crisol de razas", o de una sociedad multiétnica, al haber albergado un componente humano de diversas procedencias y jerarquías sociales.

No obstante, las condiciones de vida no fueron las mismas para aquellos que se afincaron en el Territorio como agricultores o artesanos con algún grado de calificación, que para aquellos que "transitaron" por el Chaco en condición de trabajadores temporarios, aunque finalmente terminaran formando parte del remanente que aquí arraigaba al término de sus tareas. De estos últimos grupos hablaremos especialmente, puesto que algunas cuestiones que a ellos conciernen, permiten proyectar la visión hacia el resto de los integrantes del mundo rural del Chaco en ese entonces. 


\section{La afluencia de mano de obra estacional}

Las labores inherentes al cultivo (carpida) y recolección del algodón en el Chaco fueron íntegramente manuales hasta años recientes. Ello requirió periódicamente la incorporación de fuertes contingentes de braceros para ser destinados a estas tareas, que por ejemplo para la campaña 1935-36, que fue una de las más intensas del período de auge algodonero, involucró a un total de 129.639 personas. ${ }^{1}$

Durante los primeros años dedicados al cultivo, esta demanda se cubrió con mano de obra local -en buena medida indígenas-, pero la insuficiencia numérica de los nativos y la casi continua ampliación de la superficie cultivada exigió el complemento de trabajadores que provinieron espontáneamente o incentivados por los gobiernos locales o nacionales, de provincias colindantes como Corrientes, Santa Fe, Salta o Santiago; o de países vecinos, como Paraguay.

Sólo a título ilustrativo, para 1935 los requerimientos extraordinarios calculados por el gobierno territorial para la cosecha de ese año hablaban de unas 30.000 personas, y en efecto, ingresaron para la zafra 29.407 braceros. $^{2}$ Teniendo en cuenta que la población permanente del Territorio ascendía entonces a 276.343 habitantes, esta afluencia significaba elevar repentinamente en casi un $11 \%$ el número de personas residentes en el Chaco.

Pero no sólo llegaban braceros en tales períodos; temporalmente arribaba también lo que el historiador chaqueño Guido Miranda calificó como "un ejército" de viajantes, comisionistas, vendedores y pagadores de todos los rubros que buscaban tomar su porción en este tiempo de bonanza.

El movimiento y alternancia que provocaba el auge algodonero ha sido cuantificado a través de registros portuarios y ferroviarios especialmente, y al margen de las diferencias que pueden discutirse, se ha estimado por ejemplo para los años 1934, 1935 y 1936, en 122.000, 165.000 , y 299.000 respectivamente y en cifras redondas, el número de personas que "transitaron" por este Territorio, es decir, los números totales de ingresos y egresos. Debe indicarse que en cada uno de estos movimientos periódicos, siempre quedaba un remanente de personas que aquí se radicaban. ${ }^{3}$

\footnotetext{
1. Datos tomados del Censo Algodonero de la República Argentina, 1935-1936. (ARCHIVO HISTÓRICO DE LA PROVINCIA DEL CHACO, 1936, p. 88).

2 . Cifras consignadas en Archivo Histórico de La Provincia del Chaco (1935, p. 93)

${ }^{3}$ Por ejemplo, en el año 1936 entraron al Territorio por distintas vías 299.414 pasajeros, y salieron 267.613, quedando por lo tanto un saldo favorable de 31.801 personas en el Chaco. (ARCHIVO HISTÓRICO DE LA PROVINCIA DEL CHACO, 1936a, p. 84).
} 
Estos bruscos cambios demográficos provocaban naturalmente el desborde de la administración territoriana, lo cual se evidenció de manera particular en la incapacidad para ejercer un adecuado control social.

En 1935, el constante ascenso de la superficie sembrada y los recurrentes problemas para cubrir las demandas de mano de obra impulsaron un primer intento por mejorar los controles sobre estos contingentes, tanto en lo referido a los mecanismos de atracción, como a su selección, distribución y atención durante sus períodos de permanencia en el Territorio.

El gobernador Castells creó a tal efecto una "Comisión de Braceros" y señaló las causas que lo motivaron, explayándose luego sobre la metodología que debía implementarse para garantizar no sólo un flujo óptimo de trabajadores temporarios, sino sobre todo, la selección que debía practicarse respecto a la composición de los grupos.

En tal sentido, el gobernador manifestó sus inquietudes de que entre los braceros que pudiesen venir "se filtrara gente indeseable", y al respecto, señaló en su Memoria de Gobierno:

\begin{abstract}
A esta clase de gente, el Chaco no les ofrece ambiente propicio; no los quiere ni los desea. El Chaco necesita de hombres laboriosos y no rentistas sin propiedades; hombres que luchen por la elevación moral y material de sí mismos, sin desfallecimientos, sin implorar la caridad de nadie. Para ellos el Chaco les brinda hoy y siempre, tierra apta y gratuita, y la mano protectora del estado y de los particulares[...] (ARCHIVO HISTÓRICO DE LA PROVINCIA DEL CHACO, 1935, p. 94).
\end{abstract}

Esta era, en el imaginario de un gobernador (anteriormente socialista, y ahora convertido a conservador), la idea de una fuerza laboral idónea para las tareas de zafra en el Chaco.

Pero al margen de estas expresiones de deseo, interesa conocer la verdadera situación por la que atravesaron estos grupos durante sus períodos de residencia en el Territorio, en un medio en el que estaban temporariamente desarraigados, y en el que por esta misma coyuntura, pasaban a convertirse en grupos sub-alternos, y consecuentemente, vulnerables.

Resulta de utilidad entonces recrear sus condiciones y formas de vida; su inter-relación con otros grupos integrantes de ese mundo rural y con los sectores dominantes, y sobre todo, saber en qué medida conservaron o modificaron sus costumbres (o comportamientos personales) como consecuencia de este circunstancial desarraigo y del vertiginoso frenesí que suponía la temporada de zafra algodonera.

Y si se trata de conocer algunos aspectos de la vida cotidiana en el ámbito rural, convendría tener en cuenta, por ejemplo, la información que ofrecen los registros oficiales respecto a las costumbres traídas por estos grupos desde sus lugares de origen, y a los 
hábitos (y también desviaciones) adquiridos en este medio, los cuales vistos aún desde la propia época, no dejaban de resultar llamativos.

\section{La temporalidad y la precariedad como formas de vida}

Al revisar la información oficial sobre la composición de la población rural y sus hábitos, una de las características que asoma con notoriedad, y que al mismo tiempo refleja una creciente preocupación entre las autoridades, tiene que ver por ejemplo, con informalidad difundida en las uniones de pareja, en particular, entre los grupos jornalizados.

Éstas resultaban ser 'de hecho' en un muy alto porcentaje, lo cual no sería un dato relevante si se considera la "normalidad" de esta forma de relacionarse en el mundo rural de entonces, pero el tema adquiere sin embargo importancia cuando se observa que, por el espacio que va adquiriendo en los informes, demuestra haberse convertido en un asunto preocupante para las autoridades locales, especialmente por las consecuencias negativas que ocasionaba.

La escasa predisposición hacia las uniones legales registrada en esta jurisdicción tuvo causas bien identificables, y básicamente estuvieron relacionadas con costumbres muy arraigadas dentro de estos estratos sociales; con la imposibilidad de planificar adecuadamente la organización familiar frente a la constante itinerancia entre los distintos ámbitos laborales; y también con la carencia en el Chaco -al menos hasta finales de la década del treinta-, de instituciones que alentaran los vínculos formales.

Profundizando en la explicación, debe remarcarse que en general, entre las clases más bajas de la Argentina de entonces, la unión espontánea no suponía incomodidad o pudor, como tampoco estaba suficientemente difundida la costumbre de anotar a los hijos en los registros civiles.

A su vez, entre los trabajadores "golondrina", que eran quienes participaban en las zafras de los diferentes cultivos en distintas regiones del país, la trashumancia era una forma de vida asumida, y a ello debe sumarse la movilidad constante que implicaban, en el caso específico del Chaco, las dos actividades principales: en el caso de las forestales, los hacheros debían seguir la línea de explotación del monte, abandonando repetidamente sus chozas para volver a armarlas luego en otro punto distante; y en lo referido a las tareas vinculadas a la carpida y cosecha algodonera, los braceros a su vez debían alternar de una chacra a otra al término de sus respectivas "pasadas". 
Existía además una cíclica alternancia entre una y otra "profesión" entre estos grupos jornalizados, pasando de ser hacheros a braceros, y viceversa, si la conveniencia, o simplemente las ganas así lo determinaban.

El historiador chaqueño Guido Miranda, testigo privilegiado de la época, supo describir este movimiento pendular refiriéndose, por ejemplo, a una localidad netamente forestal del Chaco, lindante con la vecina provincia de Santiago del Estero:

La población de Taco Pozo es enteramente santiagueña, y cuando llega la época de la cosecha de algodón en las colonias del Este, todos sus miembros -excepto los empleados del ferrocarril- parten en masa, dejando las calles, viviendas, fondas y almacenes vacíos, como si evacuaran ante el imaginado peligro de un ataque. La zafra algodonera no les produce mayores ganancias que el trabajo en los obrajes, si se calculan los gastos de tal movilización, pero responden a una profunda ansia espiritual de dichas gentes. No pueden resistir el paso de los trenes repletos de cosecheros que vienen de otras partes, o la invitación premiosa del hermano, la madre o el amigo que viajan en los ómnibus. Los coches hacinan una multitud increíble, que anticipa el mundo mágico de la zafra; días de trajín entre interminables líneas de algodón, recogiendo capullos bajo un sol ardiente, durmiendo en el suelo, comiendo en cuclillas[...]. Parece que toda la familia estuviese penetrada de similar anhelo de trashumancia, porque se pone en viaje íntegra, con los viejos, niños, enseres, perros, la guitarra, y hasta los pájaros domésticos[...].

A primera vista no podemos explicarnos la afición a esta vida si no es por el gusto de ambular de una chacra en otra, y por el prestigio peculiar que asumen en sus almas las reuniones que durante la noche se realizan a campo abierto, con música, juegos y recuerdos de otras cosechas, en las que se entremezcla una desprejuiciada libertad de temas y maneras[...] (MIRANDA, 1955, p. 57).

Pero desde luego, este estilo de vida nómade conspiraba contra una planificación familiar concordante con las pautas establecidas en las sociedades urbanas, y en el Chaco tampoco existían suficientes organizaciones que incentivaran el seguimiento de estas convenciones. A modo ilustrativo debe señalarse por ejemplo que la Iglesia católica, tradicionalmente inductora de la constitución y cohesión familiar, no se organizó en el Chaco sino a finales de la década del treinta, y mientras tanto, la atención religiosa fue desempeñada sólo esporádicamente por algunos misioneros, y con una muy limitada cobertura espacial. (MARI, 1999, p. 166-169) No había entonces razones para formalizar las uniones, si tampoco existía la exigencia de un mandamiento moral.

Concretamente en lo que concierne a los registros de nupcialidad en el Territorio, para los años 1934, 1935, y 1936 por ejemplo, se realizaban en promedio sólo seis enlaces legales por cada mil habitantes, aunque en algunos departamentos, dicha tasa descendía a 2,85 uniones legales por cada 1000 habitantes. (ARCHIVO HISTÓRICO DE LA PROVINCIA DEL 
CHACO, 1936b, p. 47) A su vez, las uniones religiosas realizadas en las escasas cinco parroquias y vice parroquias existentes en el Chaco, eran aún menores, totalizando sólo 345 casos para todo el Territorio durante 1935. ${ }^{4}$

Ello tenía una directa relación con la ilegitimidad de los nacimientos, con lo cual esto ya dejaba de ser solamente un "problema moral", para pasar a convertirse en una cuestión de ordenamiento social, y así lo entendió el gobernador Castells, quien preocupado por el asunto escribió en 1934:

[...] Un dato de interés que acusa la todavía deficiente formación social de nuestra población, es la cantidad extraordinaria de hijos naturales anotados en los registros civiles; pues de los 703 nacidos en abril, 345 son ilegítimos (en todo ese año hubo 7800 nacimientos). Estos datos indican la existencia de un problema de moralización y responsabilidad que nos afecta, y hay que prestarle la atención que merece [...] (ARCHIVO HISTÓRICO DE LA PROVINCIA DEL CHACO, 1934, p. 131).

Puesto que en promedio la tasa de ilegitimidad se mantuvo en el orden del $50 \%$, y en algunos departamentos del Territorio llegaba incluso al $80 \%$, en su Memoria de gobierno correspondiente a 1936 volvió a insistir con sus preocupaciones respecto a este tema:

[...] La ilegitimidad puede significar un indicador de la mayor o menor cultura de un pueblo y trae en muchos casos, consecuencias inaceptables, como por ejemplo el abandono de los hijos, que son fruto de esas uniones ilegales[...]

Al no cimentarse los lazos en que debe basarse un hogar cristiano, y producirse el abandono del padre de familia, la madre queda desamparada y los hijos mueren a poco de nacer, o se desarrollan en condiciones inapropiadas, siendo incapaces para el futuro, de ser ciudadanos aptos para el Territorio [...] A este flagelo debemos imputar la causa del aumento de la mortalidad infantil en el grupo de 1 a 5 años [...](ARCHIVO HISTÓRICO DE LA PROVINCIA DEL CHACO, 1936a, p. $60){ }^{6}$

En esta misma oportunidad, el gobernador alarmado ante las elevadas tasas de mortalidad infantil registradas, aconsejó a los poderes centrales "que se combata a tiempo el peligro que se cierne sobre quienes representan la esperanza de nuestra grandeza". (ARCHIVO HISTÓRICO DE LA PROVINCIA DEL CHACO, 1936a, p. 60).

\footnotetext{
${ }^{4}$ El número de matrimonios celebrados durante 1935 en parroquias y vice parroquias fue el siguiente: Resistencia (127); Sáenz Peña (29); Quitilipi (135); Villa Angela (24); Las Palmas (30). (ARCHIVO HISTÓRICO DE LA PROVINCIA DEL CHACO, 1935, p. 219)

${ }^{5}$ Estas eran las cifras del Departamento Tapenagá, (ARCHIVO HISTÓRICO DE LA PROVINCIA DEL CHACO, 1934, p. 124, 136).

${ }^{6}$ Cabe destacar que la tasa de mortalidad infantil fue para los años 1934,1935 y 1936, del 26,93\%; 27,76\%; y 26,78\% respectivamente. En 1935, en que se registraron 8.849 nacimientos, 891 murieron antes de cumplir un año, y 355 antes de cumplir los cinco. En 1936, con 9.493 nacimientos, murieron 886 antes del año, y 364 antes de los cinco. (ARCHIVO HISTÓRICO DE LA PROVINCIA DEL CHACO, 1936a, p. 76).
} 
Precisamente estas preocupaciones fueron, en parte, las que llevaron a Castells a impulsar la organización formal de la Iglesia en el Chaco. Aún siendo un agnóstico declarado, entendía que la acción de la misma a través de una adecuada contención espiritual, podría revertir algunas costumbres y disminuir considerablemente sus efectos negativos en la sanidad, el orden público, e incluso en la productividad laboral.

Como consecuencia de sus gestiones ante el gobierno nacional, la organización de la Iglesia católica en el Chaco comenzaría a tomar forma concreta hacia finales de su segundo período de gobierno. ${ }^{7}$

Ahora, si bien no había propensión a formalizar uniones legales (la tasa era del 4,93 por mil), durante el año 1936 se concretaron sin embargo 1.657 enlaces ante los registros civiles (un poco más de los 1.273 registrados en el año anterior), y un dato interesante es que la mayor parte de los mismos se produjo entre los meses de junio a septiembre, pero especialmente en junio y julio, cuando finalizaban los trabajos de recolección del algodón. Ello se debía fundamentalmente a que los contrayentes disponían de tiempo, y del dinero recientemente reunido en la temporada de zafra. Esto también muestra hasta qué punto incidía la actividad algodonera en la vida de estos grupos, y en la sociedad chaqueña en general. $^{8}$

${ }^{7}$ En julio de 1934, el Chaco había recibido por primera vez una visita pastoral. En ese año, el obispo de Santa Fe Monseñor Nicolás Fasolino, a cuya Diócesis pertenecían los Territorios de Chaco y Formosa, realizó una amplia gira por estas regiones.

En esta recorrida pudo constatar la pobreza material y el estado de abandono espiritual en que se encontraba este Territorio. El mismo problema había sido advertido por el gobernador Castells, quien inclinado al catolicismo luego de haberse caracterizado durante años por un cerrado agnosticismo, desempeñaría en adelante un papel fundamental en las gestiones para mejorar la instrucción religiosa en el Chaco.

Fue precisamente Castells quien se encargó de solicitarle a Fasolino que reforzara la dotación de sacerdotes, a lo cual el Arzobispo respondió: ¿y por qué no un Obispo...?

Esa era evidentemente la solución para el desamparo religioso del Chaco. Por ello es que Fasolino inició por su parte los trámites pertinentes ante la Santa Sede, y el gobernador comenzó por la suya las gestiones correspondientes ante el gobierno nacional para conseguir la creación de una Diócesis.

El 28 de julio de 1937 Castells solicitó a los ministros del interior y de relaciones exteriores y culto de la nación, la creación de un Obispado con sede en Resistencia para los Territorios de Chaco y Formosa.

Estas gestiones culminarían recién el 3 de junio de 1939, en que por la Bula Eclesiarum Omnium se dispuso erigir y constituir la Diócesis de Resistencia. El primer Obispo de esta Diócesis fue Monseñor De Carlo, quien tomaría posesión de la misma el 20 de octubre de 1940, cuando Castells ya había dejado de ser gobernador del Chaco y ocupaba entonces el cargo de Subsecretario del Ministerio del Interior.

El gobernador Castells había reclamado la creación de un Obispado en Resistencia "porque de esta forma se llenarían las necesidades espirituales del Territorio, constituído por una enorme población extremadamente heterogénea de muy reciente cimentación, que puede ser campo de descreimiento que siempre engendra perturbaciones sociales difíciles de conjurar..." (Nota de Castells a los ministros del interior y de relaciones exteriores y culto. Archivo Obispado de Resistencia. Carpeta Obispado. Nota del 28/07/1937. Citado por (GOICOECHEA, 1982, p. 130), y también (MARI, 1999, p. 166-169). Además de la bibliografía citada, puede hallarse suficiente documentación sobre la primera parte de las gestiones para conseguir la creación de la Diócesis en: Archivo General de La Nación. Fondo Documental Presidente Agustín P. Justo. Documentos Públicos. Período Presidencial. Territorios Nacionales. (1932-1938). Serie 5.5. Obispado del Chaco. Caja/doc. No 104/178-179.

${ }^{8}$ Por ejemplo, en 1934 año en el que según el censo Territorial el Chaco contaba con 214.160 habitantes, se produjeron 1.135 enlaces matrimoniales, y tomando en cuenta el mes en el que se efectuaron, se distribuyeron de la siguiente manera: Enero (51); Febrero (53); Marzo (65); Abril (85); Mayo (97); Junio (154); Julio (177); Agosto (133); Septiembre (117); Octubre (78); Noviembre (52); Diciembre (73). Vale decir que, en 
Y otro dato interesante al respecto es, por ejemplo, la nacionalidad de los contrayentes. Teniendo en cuenta que según el censo territorial de 1934 el 14,6\% de la población del Chaco era extranjera, y considerando los altos índices de masculinidad en el período (que entre los inmigrantes europeos llegó a alcanzar el 200\%), se dio desde luego un importante porcentaje de matrimonios entre hombres extranjeros con mujeres argentinas, el cual osciló para los tres años considerados, en el orden del 17\%. A su vez, la franja etaria en la que se casaban los varones iba desde los 20 a 29 años, y en el caso de las mujeres, eran mayoritariamente menores de 20 años. (ARCHIVO HISTÓRICO DE LA PROVINCIA DEL CHACO, 1936a, p. 51).

Por otra parte, si se observan las profesiones de quienes contraían enlace, se aprecia que en su amplia mayoría eran "agricultores" y "jornaleros", con lo cual, aún cuando hemos visto que no primaba la predisposición al casamiento entre estos grupos -particularmente entre los últimos-, el dato sirve para destacar su preeminencia numérica en el conjunto social del Chaco de aquel momento. ${ }^{9}$

Pero por otro lado, es posible pensar que la falta de contención de estos segmentos, sumada a un alto índice de masculinidad, hayan incidido también en otra de las cuestiones que observamos como muy llamativa en las estadísticas, cual fue el ascenso -durante el período de cosecha-, de los delitos por entonces denominados "contra la honestidad, la libertad y el estado civil", y que estaban comprendidos dentro de la tipificación general de "Delitos contra las Personas".

En este sentido, es posible apreciar en los registros oficiales, que durante los meses en los que transcurría la zafra algodonera, se elevaban súbitamente las cifras de este tipo de delitos, cuyas manifestaciones más comunes fueron los raptos, violaciones, estupros, y violaciones de domicilio.

Tomando las precauciones del caso, ya que estas agresiones no eran habitualmente denunciables dada su difícil probación, o simplemente por prejuicios de época, los datos oficiales indican que, por ejemplo, para 1936 se contabilizaron 104 de estos delitos, de los cuales 28 fueron violaciones; 18 estupros; 20 raptos, y 38 violaciones de domicilio; todos desde luego, cometidos por hombres. (ARCHIVO HISTÓRICO DE LA PROVINCIA DEL CHACO, 1936b, p. 221).

Pero sólo un año antes las cifras habían sido del doble: 208 delitos, entre los cuales hubo 42 violaciones; 21 estupros, 45 raptos; 82 violaciones de domicilio, y 15 abusos deshonestos contra menores. La lista de los victimarios, considerando sus profesiones, estaba liderada -

cifras redondas, cuando finalizaba la cosecha de algodón en los meses de Junio y Julio, se casaba el triple de personas con respecto a los meses de noviembre a febrero, durante los cuales prácticamente se paralizaban los trabajos agrícolas. (ARCHIVO HISTÓRICO DE LA PROVINCIA DEL CHACO, 1934, p. 125).

9 Según cifras oficiales, de los 1.273 enlaces producidos en 1935, 702 fueron entre contrayentes con oficio de agricultores; 199 "jornaleros"; 172 "empleados", y muy atrás le seguían otros oficios, como "comerciantes" (62), o “mecánicos” (24). (ARCHIVO HISTÓRICO DE LA PROVINCIA DEL CHACO, 1935, p. 40). 
casi obviamente-, por "jornaleros" y "peones". (ARCHIVO HISTÓRICO DE LA PROVINCIA DEL CHACO, 1935, p. 59).

Este tipo de delitos ocurría con mayor frecuencia en las áreas rurales, carentes de vigilancia en la práctica, y donde las "sanciones morales" del entorno penalizaban más bien otras conductas tradicionalmente reprobables en estos ámbitos, como la haraganería, o la falta de coraje, por ejemplo.

El problema de estos delitos, particularmente los de abuso sexual, no parece haber disminuido con el correr del tiempo, ya que todavía en 1944 el gobernador Alberto M. Castro denunciaba en su informe anual, que ésta era precisamente la cuestión más seria que se le había planteado durante su gestión. Aseguró entonces que el número de violaciones y estupros de menores de edad llegaba a 70 u 80 casos mensuales (denunciados), advirtiendo al Ejecutivo Nacional que el problema revestía "caracteres alarmantes". ${ }^{10}$

Pero también, y seguramente como una consecuencia indirecta de la falta de control social y contención espiritual, se dieron otros comportamientos muy sugestivos dentro de los grupos jornalizados del mundo rural.

Es muy posible que como resultado del "vacío" generado al término de la temporada de zafra, con la abrupta desocupación -y desorientación- que ello suponía, se manifestaran, por ejemplo, algunas conductas ciertamente sorprendentes, como por ejemplo, un elevado porcentaje de suicidios, particularmente entre las franjas económicamente activas.

Por ejemplo, en 1936 se consignaron 55 suicidios, una cifra que podría considerarse muy alta para una población aproximada de $\mathbf{2 7 6 . 0 0 0}$ habitantes, y para una época en que las expectativas de progreso material se presentaban como ilimitadas. Las causas presuntas o invocadas eran variadas ${ }^{11} \mathrm{y}$ la distribución por género era pareja, pero curiosamente, la época en que se producían con mayor intensidad eran los meses que transcurrían desde agosto a octubre, momento en que -recordemos-, se detenía la hasta entonces febril actividad agrícola.

A su vez, la franja etaria con mayor propensión al suicidio era la comprendida entre los 18 a 22 años en las mujeres, y de 23 a 30 años en los varones (ARCHIVO HISTÓRICO DE LA PROVINCIA DEL CHACO, 1936b, p. 202-204), y los medios empleados para consumar el acto eran las armas de fuego en primer lugar, seguidas por el veneno. Cabe destacar en este sentido que en los diarios locales, con cierta frecuencia aparecían publicados los casos de

10 Archivo Histórico de la Provincia del Chaco (A.H.P.Ch.) Síntesis de la labor administrativa desarrollada en la gobernación del Chaco. Gobernador Coronel Alberto M. Castro. Desde el 04/06/1943 hasta el 25 de agosto de 1944. Folio $\mathrm{N}^{\circ} 133$.

11 Se ignoran (23); disgustos de familia (7); infidelidad conyugal (6); quebrantos financieros (5); amores contrariados (5); figuraban entre las causas más comunes. (ARCHIVO HISTÓRICO DE LA PROVINCIA DEL CHACO, 1936b, p. 203). 
suicidio con "Verde París", que era un plaguicida de uso común para el algodón, y la reiteración del método llegó a tal difusión, que este nombre se utilizó incluso como tema de bromas, cuando sarcásticamente se recomendaba a algún personaje ficticio, que lo ingiera ante la adversidad de las circunstancias.

\section{Las consecuencias sobre la estructura de servicios del Territorio}

El desbordante incremento demográfico, la masividad de las cíclicas afluencias, y algunas costumbres arraigadas entre el componente humano que integró el mundo rural del Chaco tuvo, desde luego, directa repercusión en la estructura administrativa general, pero se notó con mayor nitidez en áreas tales como la sanidad y la seguridad.

Y si bien los informes gubernativos o las publicaciones oficiales de la época se esmeraron en mostrar a un Chaco cosmopolita, económicamente pujante, y abierto a las corrientes inmigratorias, con la inocultable finalidad de enaltecer gestiones personales; de atraer inversiones o mayores aportes estatales; o bien, conseguir un mejoramiento en el restrictivo régimen político Territoriano, a poco de avanzar en sus respectivas páginas comenzaba a develarse la verdadera situación de buena parte de los habitantes del mundo rural, y también, algunos atisbos de sinceramiento por parte de los funcionarios respecto a estas cuestiones.

A modo ilustrativo, en su memoria de gobierno de 1935, y a la luz de los datos que arrojaban un $27,76 \%$ de mortalidad infantil, y el mayor porcentaje de decesos ocurridos debido a la "falta de atención médica", refiriéndose a esta situación el gobernador Castells expresaba:

\footnotetext{
La asistencia social en el Territorio es completamente embrionaria, y salvo la meritoria labor desarrollada por el Hospital Regional de Resistencia, puede decirse que el Chaco vive librado a sus propios medios. Las municipalidades y comisiones de fomento destinan a ésta $100.000 \mathrm{~m} \$ \mathrm{n}$, pero ¿qué son estas cifras para una población que se acerca a los 250.000 habitantes? Es necesario algo más...

Debemos dejar a la beneficencia privada un papel subsidiario..., pero organicemos en forma eficaz y completa la Asistencia Social permanente y dirigida por el Estado, que tiene obligación indiscutible de proveer a estas grandes necesidades generales, sin perjuicio de buscar la colaboración popular [...] (ARCHIVO HISTÓRICO DE LA PROVINCIA DEL CHACO, 1935, p. 46).
}

Al año siguiente insistía advirtiendo que el Hospital Regional de Resistencia (el más importante del Territorio) era insuficiente y no llenaba las necesidades cada día más 
crecientes del Territorio. En ese momento, con una población calculada en 276.000 habitantes, el Chaco contaba con sólo 89 médicos entre titulados y "autorizados"; 22 dentistas; 58 farmacéuticos, y 11 parteras. Y según las diferentes especialidades, quienes ejercían la profesión en condición de "autorizados" (es decir sin título habilitante), oscilaban entre un 10 y un 50\%. (ARCHIVO HISTÓRICO DE LA PROVINCIA DEL CHACO, 1936b, p. 422).

Y remarcaba Castells en este sentido:

Zonas extensas de nuestro Territorio, con numerosa población, no saben lo que es un médico, y a ello se debe que en nuestras estadísticas figuren elevadas cifras de fallecidos `sin asistencia médica`...

Es necesario que las autoridades de nuestras Universidades encaminen hacia estas tierras a los jóvenes facultativos, e igualmente, el Departamento Nacional de Higiene podría hacer propaganda en este sentido. (ARCHIVO HISTÓRICO DE LA PROVINCIA DEL CHACO, 1936b, p. 414).

Para este momento, las enfermedades más comunes, y consecuentemente las que propiciaban la mayor cantidad de fallecimientos eran las respiratorias (bronconeumonía y tuberculosis principalmente). Estaban también extendidas con carácter endémico las venéreas, sobre todo la sífilis, aunque éstas no necesariamente producían desenlaces fatales. $^{12}$

Pero un dato curioso estaba dado por las altas cifras consignadas como "muertes producidas por factores externos" ( $4^{\circ}$ lugar en las estadísticas), y entre sus desencadenantes principales, no figuraban precisamente los accidentes, sino la agresión con armas blancas y de fuego. Sólo como dato ilustrativo, debe señalarse que en 1936 se produjeron en el Chaco 238 homicidios, y esta cifra habla por sí misma al reflejar un grave problema de inseguridad, sobre todo en las áreas rurales, y también, una arraigada costumbre de dirimir los pleitos a través de formas violentas. ${ }^{13}$

\footnotetext{
${ }^{12}$ En su informe del año 1915, el inspector nacional de trabajo había advertido sobre los alcances de este flagelo en el Chaco:

"Las enfermedades originadas en el contacto sexual están muy difundidas en el Chaco, y la sífilis presenta aquí caracteres extremadamente graves, diseminada por la libre prostitución, e impuesta por la herencia. Difícilmente se encontrarán sujetos de cierta edad que no padezcan enfermedades venéreas.

No hay atención sanitaria en los obrajes forestales, y a esto se suma el abandono personal. El asunto merece empeñosa dedicación. Debe ordenarse a las autoridades sanitarias locales hacer giras periódicas por los obrajes para aminorar el inmenso mal de la prostitución libre. Es indispensable, apremiante, que se prohíba el ejercicio de la prostitución a las mujeres enfermas, y debe agregarse un Sifilocomio a los servicios hospitalarios de la región" (NIKLISON, 1915, p. 133).

${ }^{13}$ Cifra consignada en (ARCHIVO HISTÓRICO DE LA PROVINCIA DEL CHACO, 1936a, p. 215).

Las cifras revelan que la mayoría de los casos de homicidio en riña se produjeron entre los meses de marzo a julio, es decir el período de zafra algodonera, donde la afluencia de cosecheros era mayor. Allí se tienen los picos más altos, con 26 muertes en el mes de mayo, mientras que en septiembre ocurrieron sólo 4 . De la misma manera, el mapa de los homicidios revela que los mismos se cometieron en las áreas circundantes a los centros algodoneros más importantes, como Sáenz Peña y Quitilipi por ejemplo. A su vez, el 83,83\% de estos homicidios fue cometido por jornaleros y agricultores, lo cual confirma que este tipo de delito se producía como directa consecuencia del tumultuoso frenesí de la cosecha.
} 
El propio Castells había advertido en reiteradas ocasiones que había que limitar la portación de armas, algo muy común en las zonas rurales, ya que ello ocasionaba elevados porcentajes de hechos de sangre. ${ }^{14}$

Tabela 1: Principales causas de fallecimientos

\begin{tabular}{llll}
\multicolumn{1}{c}{$\underline{\text { Años }}$} & $\underline{\mathbf{1 9 3 4}}$ & $\underline{\mathbf{1 9 3 5}}$ & $\underline{\mathbf{1 9 3 6}}$ \\
\hline Totales & 2.544 & 3.213 & 3.309 \\
1. Sin asistencia médica & 481 & 425 & 451 \\
2. Afecc. aparato respiratorio & 364 & 357 & 427 \\
3. Enf. epidémicas e infecc. & 362 & 497 & 530 \\
4. Por causas externas & 300 & 539 & 370
\end{tabular}

Fuente: Memorias de Gobierno de José Castells correspondientes a esos años.

Si se analizan las estadísticas oficiales, y se cotejan las áreas en donde se agudizaban estos problemas y los sectores sociales involucrados en ellos, se comprueba que toda esta problemática sanitaria y de seguridad estaba directamente relacionada con la desbordante afluencia humana ocasionada por el fenómeno algodonero, y adquiría sus manifestaciones más agudas, lógicamente, en los ámbitos rurales. ${ }^{15}$

Mientras tanto los gobernadores, al momento de elaborar sus informes, se debatieron entre la disyuntiva de presentar un Territorio próspero y civilizado, o bien advertir con mayor insistencia acerca de problemáticas que serían fácilmente solucionables si las

\footnotetext{
${ }^{14}$ A la luz de los reveladores datos oficiales, el gobernador Castells solicitó asesoramiento al jefe de la policía de la capital federal: "...La gobernación del Territorio Nacional del Chaco se propone solicitar del Poder Ejecutivo, la adopción de medidas destinadas a restringir el abuso que importa la portación de armas que autoriza el Código Rural sancionado en 1894, y que ya no responde a las necesidades de los mismos... A fin de documentar ampliamente las medidas que habrán de proponerse y con el propósito de estudiar las reglamentaciones existentes al respecto en la capital federal, es que me permito solicitar a ud., todas las disposiciones vigentes sobre portación de armas, rogando por razones de premura sirva ordenar que el envío se lleve a cabo a la mayor brevedad..." (ARCHIVO HISTÓRICO DE LA PROVINCIA DEL CHACO, 1934).

${ }^{15}$ Según lo consigna la Memoria Gubernativa del año 1934, de 2.544 decesos totales en el Chaco, excluyendo el renglón señalado como "sin asistencia médica", puede observarse la siguiente escala en cuanto a las causas principales: Bronconeumonía (233 casos); Tuberculosis pulmonar (171 casos). Los fallecidos por herida de armas de fuego (Incluyendo los accidentes) fueron 156, mientras que los fallecidos por heridas de arma blanca fueron 64. (ARCHIVO HISTÓRICO DE LA PROVINCIA DEL CHACO, 1934, p. 150). En 1935, entre 3.213 decesos, y excluyendo los 525 consignados como "sin asistencia médica", los fallecidos a consecuencia de heridas de armas de fuego pasan al segundo lugar, con 165 casos, luego de la Bronconeumonía que causó 246 muertes. En este año, los fallecimientos por heridas de arma blanca suman 79 casos.( ARCHIVO HISTÓRICO DE LA PROVINCIA DEL CHACO,1935, p. 50-51). En 1936, entre 3.309 defunciones, aunque no se detallan específicamente las causas de muerte, en la Memoria de Gobierno de este año figuran 370 casos producidos por "causas externas", es decir -y según el propio documento-, decesos producidos mayoritariamente por heridas de armas de fuego y blancas.(ARCHIVO HISTÓRICO DE LA PROVINCIA DEL CHACO,1936a, p. 77).
} 
autoridades centrales retornaran al Chaco un mayor porcentaje de la formidable rentabilidad que se generaba en éste, con las actividades forestales y algodoneras. ${ }^{16}$

Un ejemplo de ello puede observarse en la Memoria de Gobierno de Gustavo Lagerheim (1938-41), en la que contradiciendo el inicial (y aparentemente inmejorable) panorama trazado en las primeras páginas respecto al Chaco, al referirse por ejemplo a la sobrecarga de tareas que tenía la policía local, el funcionario se sinceraba y añadía una visión más completa -y más realista- sobre la cuestión social:

\begin{abstract}
La infancia desvalida y vagabunda, la mendicidad, los ancianos desamparados, y los dementes, reflejan problemas sociales cuyas soluciones no competen únicamente a la policía, pero es indudable que incide en su tarea, y que una vez resuelta con la creación de la alcaidía, asilos, y otros establecimientos similares, se aliviará grandemente la labor para el personal y desaparecerán los cuadros poco edificantes que contemplamos a diario, impotentes de remediarlos.

El progreso del Chaco, que ha alcanzado tan altos niveles en todos los aspectos, no se hace presente con la pujanza que debiera en estos asuntos de asistencia social. (ARCHIVO HISTÓRICO DE LA PROVINCIA DEL CHACO, 1940, p. 35).
\end{abstract}

Y ésta última frase refleja precisamente el sentido del párrafo inicial del presente, en el que se cita la observación de Juan Ramón Lestani, que a la sazón, y en buena medida movido por sus ideas socialistas y su compromiso como nativo de esta jurisdicción, supo diagnosticar certeramente buena parte de la problemática del Chaco, y con sus escritos, logró poner en debate asuntos hasta entonces relegados en la agenda local, como por ejemplo los vinculados a la cuestión social.

Los años venideros ofrecerían un mejor escenario para el tratamiento de estos temas, en sintonía con los nuevos vientos que soplarían durante la segunda mitad de la década del cuarenta. La emergencia del peronismo aportando otros paradigmas sobre el manejo de las cuestiones sociales, y la necesidad de efectivizar reformas pendientes en los Territorios Nacionales de la Argentina, tenderían a "normalizar" los conceptos de asistencialismo e

\footnotetext{
${ }^{16}$ En 1940 las diez municipalidades entonces constituidas en el Chaco recaudaban por multas, patentes y tributos la suma de $2.014 .072 \$$, frente a los escasos $1.468 .500 \$$ otorgados como presupuesto total a la gobernación en el mismo año. Otro dato ilustrativo: En 1925 el valor de la producción de una cosecha algodonera normal era de 17 millones de pesos y el presupuesto para la gobernación del Chaco era de 1.501.700\$; En 1938, el valor de esa producción ascendía a 53 millones, mientras que el presupuesto -que descendió considerablemente desde 1931 hasta 1936, en que fue reajustado-, estaba en el orden de los 1.431.127\$. Para establecer una comparación; en 1940 el presupuesto total de la Gobernación del Chaco se mantenía en $1.468 .500 \$$, de los cuales 1.088 .820 \$ eran destinados al pago de salarios del personal policial. Como se observa, si bien el grueso del presupuesto territoriano estaba destinado a los sueldos de la policía, no existía una relación proporcional entre esta erogación en particular y los gastos generales del Territorio, respecto a su aporte económico total al erario nacional, y menos aún, teniendo en cuenta la considerable multiplicación de su población. (ARCHIVO HISTÓRICO DE LA PROVINCIA DEL CHACO, 1936a).
} 
inclusión, permitiendo así incorporar a estos postergados sectores del mundo rural a mejores condiciones de vida y trabajo.

\section{A manera de síntesis}

El surgimiento y difusión del cultivo algodonero significó para el Chaco no sólo un cambio de ciclo económico mediante la transición de un modelo extractivo a uno productivo, sino sobre todo, una efervescente etapa en la cual se produjeron periódicas y masivas afluencias humanas que fueron atraídas por el exitoso proceso.

Estas cíclicas afluencias, compuestas mayoritariamente por trabajadores manuales provenientes de regiones vecinas, generaron por sus grandes volúmenes y el repentinismo de sus ingresos, los problemas propios de las abruptas migraciones en espacios de reciente ocupación, e insuficientemente organizados.

El desborde de la administración local fue una consecuencia esperable en estas circunstancias, y la estructura sanitaria y de seguridad fueron en este sentido, las más afectadas.

En los hechos, tal situación se tradujo en súbitos ascensos en los índices de mortalidad, ilegitimidad, e inseguridad, debido a la insuficiencia o a las deficiencias en materia de asistencia y control social.

Y aunque el Chaco de entonces ofreció inmejorables oportunidades de progreso material a quienes venían a participar del proceso algodonero, sus condiciones de vida no hallaron sin embargo, un correlato lógico, y se caracterizaron por la precariedad y la marginación, situación que fue puesta de manifiesto a través de la contundencia de los datos estadísticos, y los testimonios de los propios actores públicos.

Y aquí es donde cobran sentido las palabras "oro y miseria" con las que el escritor Juan Lestani definiera los contrastes que observaba en el Chaco de esta época.

Frente a la problemática generada por estos bruscos movimientos, los dirigentes locales del momento adoptaron diversas posturas. Unos optaron por advertir y denunciar la vulnerabilidad de estos grupos humanos a través de la palabra escrita en medios de difusión locales, o en publicaciones ocasionales de alcance limitado. Los acertados diagnósticos no estuvieron sin embargo desprovistos de propuestas de solución, aunque éstas no siempre fueron viables. El ejemplo más representativo en este sentido, fue el del periodista chaqueño Juan R. Lestani. 
Otros, en cambio, exigidos por el rol ejecutivo que circunstancialmente debieron desempeñar, decidieron involucrarse más activamente y de manera concreta en la cuestión social surgida como consecuencia del auge algodonero en el Chaco. Este fue el caso de José Castells, quien en su condición de gobernador durante dos períodos consecutivos, y poniendo en práctica sus excepcionales cualidades profesionales, se ocupó de estudiar cuidadosamente los alcances del problema. Ya con datos metódicamente obtenidos, insistió en reclamar, proponer y gestionar ante los poderes centrales, las soluciones posibles para encausar este desbordante proceso socioeconómico.

Otros protagonistas de la época se limitaron simplemente a informar a las autoridades nacionales acerca de la dimensión que había adquirido la problemática social en el Territorio, señalando ocasional y tibiamente, las medidas que debían instrumentarse para enmendar las deficiencias en esta materia.

Pero de todas formas, e independientemente de la viabilidad o eficacia de sus propuestas y/o acciones, algunos integrantes del núcleo dirigente local lograron colocar por primera vez el tema social en la agenda de discusiones del Chaco, propiciando de esta manera un incipiente debate público que hasta ese momento no se había dado.

La falta de resolución de algunos de los problemas planteados debe enmarcarse, no obstante, en las limitaciones propias de la época, y del régimen político de un espacio periférico casi enteramente tutelado. La escasa sensibilidad que por entonces despertaban las cuestiones vinculadas a la temática social, y la excesiva dependencia de la dirigencia local ante las autoridades centrales, ralentizaron o disminuyeron la efectividad de algunas buenas iniciativas para corregir las deficiencias apuntadas.

La década del cuarenta, sobre todo su segunda mitad, presentaría un escenario más adecuado para discutir y resolver las cuestiones sociales en el marco de los nuevos paradigmas formulados al respecto por el emergente peronismo, y también, ante el impostergable tratamiento de reformas políticas pendientes referidas a los Territorios Nacionales argentinos. Será precisamente en ese momento en el que se crearán o instrumentarán con mayor eficacia, mecanismos de control social más adecuados para dar contención e incluir a estos grandes grupos que terminarán finalmente, aportando su acervo cultural de origen a la identidad colectiva del Chaco.

\section{Bibliografia}

ARCHIVO GENERAL DE LA NACIÓN. Fondo Documental Presidente Agustín P. Justo. Documentos Públicos. Período Presidencial. Territorios Nacionales. (1932-1938). Serie 5.5. Obispado del Chaco. Caja/doc. N ${ }^{\circ}$ 104/178-179. 
ARCHIVO GENERAL DE LA NACIÓN. Fondo Documental Presidente Agustín P. Justo. Documentos públicos período presidencial. Territorios Nacionales (1932-1938). Situación Socio-Política. Caja $\mathrm{N}^{\circ} 63$, documento $\mathrm{N}^{\circ} 3$.

ARCHIVO HISTÓRICO DE LA PROVINCIA DEL CHACO. Censo algodonero de la República Argentina, 1935-1936. Álgodon: Ministerio de Agricultura, Junta Nacional del Algodón, 1936a.

ARCHIVO HISTÓRICO DE LA PROVINCIA DEL CHACO. Informe del inspector del departamento del trabajo, José Elías Niklison. Boletín del Departamento Nacional del Trabajo, Buenos Aires, n. 32, p. 2-147, 1915.

ARCHIVO HISTÓRICO DE LA PROVINCIA DEL CHACO. Informe sobre el estado de las clases obreras en el interior de la República por el Dr. Juan Bialet Massé. Buenos Aires: Imprenta de Adolfo Grau, 1904.

ARCHIVO HISTÓRICO DE LA PROVINCIA DEL CHACO. Memoria de gobierno de 1940 presentada por el gobernador Gustavo R. Lagerheim. Resistencia: Oficina de Estadística de la Gobernación, 1942.

ARCHIVO HISTÓRICO DE LA PROVINCIA DEL CHACO. Memoria presentada al superior gobierno de la nación por el gobernador José Castells, correspondiente al año 1934. Resistencia, 1935.

ARCHIVO HISTÓRICO DE LA PROVINCIA DEL CHACO. Memoria presentada al ministerio del interior por el gobernador del territorio nacional del Chaco, José Castells, correspondiente al año1935. Resistencia: Gobernación del Chaco, 1936b.

ARCHIVO HISTÓRICO DE LA PROVINCIA DEL CHACO. Memoria presentada al superior gobierno de la nación por el gobernador José Castells, correspondiente al año 1936. Resistencia: Juan Moro, 1937.

ARCHIVO HISTÓRICO DE LA PROVINCIA DEL CHACO. Síntesis de la labor administrativa desarrollada en la gobernación del Chaco. Gobernador Coronel Alberto M. Castro. Desde el 04/06/1943 hasta el 25 de agosto de 1944. Folio No 133.

ARCHIVO HISTÓRICO DE LA PROVINCIA DEL CHACO.Copiadores de la Secretaría de la Gobernación del Chaco. Chaco, 1934.

BECK, Hugo Humberto. Inmigrantes europeos en el Chaco. Transición del pluralismo al crisol. Cuadernos de Geohistoria Regional, Resistencia, n. 39, 2001.

BORRINI, Héctor. La Colonización como Fundamento de la Organización Territorial del Chaco (1930-1953). Cuadernos de Geohistoria Regional, Resistencia, n. 19, 1987.

BRUNIARD, Enrique. El Gran Chaco Argentino (Ensayo de Interpretación Geográfica). Geográfica, Resistencia, n. 4, 1978.

BUNSTORF, Jürgen. El papel de la industria taninera y de la economía agropecuaria en la ocupación del espacio chaqueño. Folia Histórica del Nordeste, Resistencia-Corrientes, n. 5, p. 103-120, 1982. 
GIRBAL, Noemí. Crisis obrajera, estrategias sectoriales y condiciones de trabajo en el Gran Chaco Argentino (1918-1930). Folia Histórica del Nordeste, Resistencia, n. 5, p. 5-30, 1993.

GOICOECHEA, Nilda. El episcopado de Monseñor Nicolás De Carlo: su obra social. Folia Histórica del Nordeste, Resistencia, n. 5, p. 130, 1982.

IÑIGO CARRERA, Nicolás et al. El campo y sus habitantes. Buenos Aires: Centro Editor de América Latina, 1986.

IÑIGO CARRERA, Nicolás. Fracciones y capas en el proletariado chaqueño 1910-50. Los obreros de las desmotadoras de algodón. Programa de Investigación sobre el movimiento de la sociedad argentina PIMSA. Buenos Aires: PIMSA, 1997. (Documento de trabajo, n. 8).

IÑIGO CARRERA, Nicolás. La colonización del Chaco. Buenos Aires: Centro Editor de América Latina, 1983.

LESTANI, Juan Ramón. El territorio nacional del Chaco: geográfico, económico, social. (oro y miseria). Resistencia: [S. n.], 1935.

LESTANI, Juan Ramón. Por los caminos del Chaco. Resistencia: Librería de la Paz, 2010.

MAEDER, Ernesto J. Historia del Chaco. Buenos Aires: Plus Ultra, 1997. (Colección Historia de Nuestras Provincias, n. 18).

MARI, Oscar Ernesto. El territorio nacional del Chaco durante la etapa conservadora 19301943. Cuadernos de Geohistoria Regional, Resistencia, n. 37, 1999.

MIRANDA, Guido. Tres ciclos chaqueños. Resistencia-Chaco: Norte Argentino, 1955. (Crónica Histórica Regional).

NIKLISON, José Elías. Boletín del Departamento Nacional del Trabajo, Buenos Aires, n. 32, p. 2$147,1915$.

OSPITAL, María Silvia. Condiciones laborales en la explotación forestal del Gran Chaco Argentino (1890-1920). Folia Histórica del Nordeste, Resistencia, n. 9, p. 5-23, 1990.

PAVLOTZKY, José. Esta tierra es mía. Buenos Aires: El Ateneo, 1947.

POMPERT DE VALENZUELA, María Cristina. Memorias del Chaco forestal. Corrientes: Moglia, 2010.

SCHALLER, Enrique. La colonización en el territorio nacional del Chaco en el período 1869-1921. Corrientes: IIGHI-CONICET, 1986.

SUÁITER MARTÍNEZ, Francisco. Los Territorios. Buenos Aires: Instituto Cultural Joaquín V. González, 1943. 